\title{
Intermediate Risk of Choledocholithiasis: Are we on the right path?
}

Felipe Giron

Universidad del Rosario

Lina M Rodriguez

Universidad de los Andes, Bogotá D.C

Danny Conde

Hospital Universitario Méderi

Carlos Rey ( $\nabla$ carlosrey991@gmail.com )

Universidad del Rosario

Marco Vanegas

Universidad del Rosario

David Venegas

Universidad del Rosario

Fernando Gutierrez

Universidad del Rosario

Ricardo M Nassar

Universidad del Rosario

Daniel Jimenez

Universidad del Rosario

Susana Rojas

Hospital Universitario Méderi

\section{Research Article}

Keywords: Cholelithiasis, choledocholithiasis risk, MRCP, ASGE guidelines

Posted Date: May 10th, 2022

DOI: https://doi.org/10.21203/rs.3.rs-1290002/v2

License: (1) This work is licensed under a Creative Commons Attribution 4.0 International License.

Read Full License 


\section{Abstract}

\section{Background}

Risk of choledocholithiasis should be assessed in every patient who must undergo cholecystectomy to define the next step. American Society for Gastrointestinal endoscopy (ASGE) proposed a stratified predictor scale of choledocholithiasis.

\section{Methods}

To describe our experience managing patients with intermediate risk of choledocholithiasis according to the ASGE guidelines and actual presence of bile duct stones in magnetic resonance cholangiopancreatography. A retrospective observational study with a prospective database was conducted. Analysis included socio demographic data, laboratory values and imaging. Bivariate, multivariate and ROC analysis was performed.

\section{Results}

327 patients had intermediate risk for choledocholithiasis. Half the patients were at least 65 years old. $24.8 \%$ were diagnosed with choledocholithiasis. Bile duct dilation was documented in only $3.06 \%$ of cases. Diagnosis of choledocholithiasis is associated with age OR: 1.87 (p 0.02), alkaline phosphatase OR: 2.44 ( $p$ 0.02) and bile duct dilation > 6 mm OR: 14.65 ( $p$ 0.00).

\section{Conclusions}

High variability in accuracy of imaging techniques results in a large number of patients classified as intermediate risk without choledocholithiasis in cholangio-resonance. Therefore, enhancing the criteria to define intermediate risk for patients in order to optimize resources is of paramount importance.

\section{Background}

The gallbladder is a small pouch that sits under the liver and stores bile [1]. Bile aids in the fat digestion process, during which cholesterol can deposit and form thick crystals (sludge) or stones (gallstones), formation of stones in the gallbladder is called cholelithiasis [1,2]. Additionally, gallstones can get plunged in the gallbladder, in the cystic duct, or in the common bile duct [1,2]. Cholelithiasis is a common disease, occurring in $5-22 \%$ people in the western countries, among $8-20 \%$ combined with common bile duct stone (CBDS) [3, 4]. choledocholithiasis is the presence of stones in the bile duct, commonly associated with cholelithiasis, with an incidence of $5-18 \%[5,6]$. However, it also presents in patients with a history of cholecystectomy, with an incidence of 10 to $18 \%$ [7]. choledocholithiasis is a frequent cause of hospitalization which may lead to cholangitis and gallstone pancreatitis [3].

To avoid pancreatitis and cholangitis, every patient with cholelithiasis planning to undergo cholecystectomy, should have its risk of preoperative choledocholithiasis figured, thus defining the next 
step, which can be either surgical or endoscopic [5]. Therefore, the American Society for Gastrointestinal endoscopy (ASGE) proposed some predictors based on ultrasound findings, liver function tests, and the presence of pancreatitis and/or cholangitis (Fig. 1) [8, 9]. According to the ASGE criteria, patients with cholelithiasis have been classified as having high, intermediate or low risk of concomitant choledocholithiasis [9]. The most controversial group are the patients classified as intermediate risk due to a wide range of diagnostic and management pathways[8]. According to the flow chart proposed by ASGE, patients with low risk of choledocholithiasis should undergo cholecystectomy, while patients with high risk of choledocholithiasis should undergo endoscopic retrograde pancreatography as a diagnostic and therapeutic procedure [10,11]. ASGE score is widely used worldwide, and the 2019 update is focused on reducing the amount of unnecessary endoscopic retrograde cholangio-ancreatography (ERCP) but not the unnecessary use of the magnetic resonance cholangio-pancreatography (MRCP) [12]. Intermediate risk involves a large proportion of patients, therefore impacting prompt management and increasing health costs [13].

The intermediate risk group for choledocholithiasis constitutes a therapeutic challenge, due to possible need of presurgical biliary imaging [12-13]. MRCP, has a $85 \%-92 \%$ sensitivity and $93 \%-97 \%$ specificity $[14,15]$ but it requires the provision of a resonator, the time to perform it, increased costs and the interpretation of an experienced radiologist $[11,12,13]$. It is worth clarifying that the gold standard for the diagnosis of choledocholithiasis is ERCP, but with non-negligible risks (5-10\% morbidity) thus, it should be limited to high risk patients [14]. On the other hand, despite its high sensibility the use of endoscopic ultrasound is not widely available and is limited to some institutions $[15,16,17]$.

The purpose of this study is to describe our experience in the diagnosis process of patients with intermediate risk of choledocholithiasis according to the ASGE guidelines and the confirmation of bile duct stones with magnetic resonance cholangiopancreatography (MRCP).

\section{Methods}

Following Institutional Review Board approval, all patients over 18 years old who were diagnosed with medium risk of choledocholithiasis according to the 2019 ASGE guidelines between January and December 2019, were registered (Fig. 2). We exclude patients with micro-choledocholithiasis. The present study was performed in a single institution, two experienced radiologists perform all cholangio-resonance interpretations. By protocol, all patients who were classified with intermediate risk of choledocholithiasis underwent cholangio resonance pre-operatively, and if the diagnosis was made, ERCP was performed prior to cholecystectomy. Intraoperative cholangiography was not performed in any case, if choledocholithiasis persisted, bile duct exploration was performed by an hepatobiliary and pancreatic surgeon and was excluded from the study. Patients with acute pancreatitis or acute cholecystitis were classified according to international classifications; Marshal and Tokyo severity score respectively. Bile duct dilation cutoff was established in our institution greater than 6 millimeters according to worldwide literature.. A retrospective analysis of patients who complied with inclusion criteria was made for the study. Ethical compliance with the Helsinki Declaration, current legislation on research Res. 008430 - 
1993 and Res. 2378 - 2008 (Colombia) and the International Committee of Medical Journal Editors (ICMJE) were ensured under our Ethics and Research Institutional Committee (IRB) approval.

Data obtained included patients demographics, liver function tests, additional diseases, imaging studies obtained and its results. Descriptive statistics of all study parameters were provided. Data was analyzed using STATA 17 software. Continuous data were summarized by their mean, standard deviation, median and interquartile range. Categorical data were summarized by their frequency and proportion. Bivariate analysis was performed. Qualitative variables were analyzed using chi-square statistics (Fisher's exact test when appropriate). Quantitative variables were analyzed, based on normality, with Spearman's or Pearson's associations correlation coefficient accordingly. Bivariate analysis between qualitative and quantitative variables was performed using Mann-Whitney test and t-test for independent samples. Binary multivariate analysis was performed with significant variables found in the bivariate. ROC analysis was used to determine cutoff points for relevant liver tests, a new multivariate analysis was performed with new cutoff points.

\section{Results}

From January to December 2019, a total of 342 patients with biliary disease were classified as having intermediate risk of choledocholithiasis. 15 patients were excluded as they were initially misclassified as intermediate risk, obtaining a total of 327 patients with intermediate risk of choledocholithiasis according to the ASGE 2019 guidelines [12]. Median age was 65 (iqr 20) years old, $70,72 \%$ were female and 29,28\% male. Half the patients had a time of symptomatology onset to consultation of 2 days. Within the paraclinical tests, leukocytosis was an important parameter, with $50 \%$ of patients presenting more than $10,760 / \mathrm{mm} 3$ (iqr 5,705) leukocytes. Median total bilirubin was $1.415 \mathrm{mg} / \mathrm{dL}$ (iqr 1.505), usually at the expense of direct bilirubin with a median of $0.755 \mathrm{mg} / \mathrm{dL}$ (iqr 1.105). Liver profile was slightly altered in our population, with median AST, ALT, and alkaline phosphatase of 121 (iqr 291), 127 (iqr 287.5) and 165 (iqr 156) IU/L, respectively (Table 1 ). 
Table 1

Quantitative descriptive characteristics

\begin{tabular}{|llll|}
\hline Variables & Obs & Median & iqr. \\
\hline Age & 327 & 65 & 21 \\
\hline Duration of symptoms & 324 & 2 & 4 \\
\hline Leukocytes & 326 & 10745 & 5640 \\
\hline Total bilirubin & 324 & 1.415 & 1.505 \\
\hline Direct bilirubin & 324 & 0.755 & 1.105 \\
\hline Indirect bilirubin & 325 & 0.47 & 0.47 \\
\hline AST & 321 & 121 & 291 \\
\hline ALT & 320 & 127 & 287.5 \\
\hline Alkaline phosphatase & 315 & 165 & 156 \\
\hline
\end{tabular}

All patients underwent magnetic resonance cholangiography, while the vast majority $(97.5 \%)$ had a previous hepatobiliary ultrasound (Table 2). Of the $100 \%$ of patients taken to MRI cholangiography, only $24.8 \%$ were diagnosed with choledocholithiasis (Table 2). $37.6 \%$ of the patients presented with cholecystitis, among which, $52.03 \%$ had a severity according to the Tokyo scale of II. $25.68 \%$ patients presented with pancreatitis at the time of diagnosis, the majority $(47.6 \%)$ with a severity and organic failure according to the marshall scale of II (Table 2). A significant percentage of patients (48\%) had previous intra-abdominal surgery, $10.7 \%$ were type 2 diabetic and $2.44 \%$ suffered from kidney disease. 
Table 2

Qualitative descriptive characteristics by sex

\begin{tabular}{|c|c|c|c|}
\hline Variable & & $\mathbf{n}$ & $\%$ \\
\hline \multirow[t]{2}{*}{ Gender } & Male & 96 & 29,4 \\
\hline & Female & 231 & 70,6 \\
\hline \multirow[t]{2}{*}{ Renal disease } & Yes & 8 & 2,4 \\
\hline & No & 319 & 97,6 \\
\hline \multirow{2}{*}{$\begin{array}{l}\text { Previous } \\
\text { surgical intervention }\end{array}$} & Yes & 157 & 48,0 \\
\hline & No & 170 & 52,0 \\
\hline \multirow{2}{*}{$\begin{array}{l}\text { Murphy sign } \\
\text { positive }\end{array}$} & Yes & 85 & 26,0 \\
\hline & No & 242 & 74,0 \\
\hline \multirow[t]{2}{*}{ Cholecystitis } & Yes & 123 & 37,6 \\
\hline & No & 204 & 62,4 \\
\hline \multirow[t]{3}{*}{ Cholecystitis Severity } & Tokio I & 22 & 6,7 \\
\hline & Tokio II & 64 & 19,6 \\
\hline & Tokio III & 15 & 4,6 \\
\hline \multirow[t]{2}{*}{ Pancreatitis } & Yes & 84 & 25,7 \\
\hline & No & 243 & 74,3 \\
\hline \multirow[t]{5}{*}{ Pancreatitis Severity } & Marshall 0 & 6 & 1,8 \\
\hline & Marshall 1 & 28 & 8,6 \\
\hline & Marshall 2 & 40 & 12,2 \\
\hline & Marshall 3 & 5 & 1,5 \\
\hline & Marshall 4 & 3 & 0,9 \\
\hline \multirow[t]{2}{*}{ Ultrasound } & Yes & 319 & 97,6 \\
\hline & No & 8 & 2,4 \\
\hline \multirow{2}{*}{$\begin{array}{l}\text { Magnetic } \\
\text { Resonance } \\
\text { Cholangiopancreatography }\end{array}$} & Yes & 327 & 100,0 \\
\hline & No & 0 & 0,0 \\
\hline \multirow{2}{*}{$\begin{array}{l}\text { Choledocholithiasis } \\
\text { Diagnosis }\end{array}$} & Yes & 81 & 24,8 \\
\hline & No & 246 & 75,2 \\
\hline
\end{tabular}


Ultrasound findings indicated the presence of stones in the gallbladder or common bile duct, as well as the presence or absence of cholecystitis and bile duct dilation. According to these imaging findings, $49.38 \%$ of the patients had an ultrasound imaging diagnosis of cholelithiasis, $29.32 \%$ had concomitant cholecystitis and only $1.54 \%$ of the patients with bile duct dilation were reported in this initial study (Table 3). Among the patients taken to MRCP, a diagnosis of cholelithiasis was made in $32.42 \%$ of the patients. $25.08 \%$ had concomitant cholelithiasis and cholecystitis. Regarding the dilation of the bile duct, the percentage was $3.06 \%$ (Table 4).

Table 3

US Findings

\begin{tabular}{|lll|}
\hline & Freq. & Percent \\
\hline No & 5 & 1.54 \\
\hline Cholelithiasis & 268 & 82.7 \\
\hline Cholecystitis & 3 & 0.9 \\
\hline Bile duct dilation & 5 & 1.54 \\
\hline Biliary sludge or Microlithiasis & 10 & 4.6 \\
\hline Normal & 25 & 7.72 \\
\hline Technical difficulties & 3 & 0.9 \\
\hline Total & 319 & 100.00 \\
\hline
\end{tabular}

Table 4

MRCP Findings

\begin{tabular}{|lll|}
\hline & Freq. & Percent \\
\hline Cholelithiasis & 186 & 56.8 \\
\hline Choledocholithiasis & 81 & 24.8 \\
\hline Cholecystitis & 3 & 0.91 \\
\hline Bile duct dilation & 10 & 3.05 \\
\hline Pancreatitis & 18 & 5.50 \\
\hline Normal & 18 & 5.50 \\
\hline Neoplasm & 9 & 2.75 \\
\hline Pancreatitis & 2 & 0.61 \\
\hline Total & 327 & 100.00 \\
\hline
\end{tabular}

Page $7 / 16$ 
Bivariate analysis was performed including the ASGE score variables for intermediate risk. Alkaline phosphatase OR: 1.00 ( $p$ 0.023), bile duct dilation > than $6 \mathrm{~mm}$ OR:12.48 $(p=0.000)$, age OR: $1.02(p=$ $0.01)$ and total bilirubin OR: $1.00(p=0.04)$ showed association with statistical significant value in the diagnosis of choledocholithiasis. Multivariate analysis with those variables was performed, results are summarized in Table 5.

Table 5

Bivariate analysis

\begin{tabular}{|llll|}
\hline Variable & Odds Ratio & IC 95\% & p \\
\hline Age & 1.02 & $1.004-1.03$ & 0.01 \\
\hline Alkaline Phosphatase & 1.00 & $1.002-1.003$ & 0.023 \\
\hline Bile duct > 6 mm & 12.48 & $3.97-39.18$ & 0.000 \\
\hline AST & 1.00 & $0.99-1.007$ & 0.156 \\
\hline ALT & 1.00 & $0.99-1.001$ & 0.07 \\
\hline Total Bilirubin & 1.00 & $0.81-1.24$ & 0.04 \\
\hline
\end{tabular}

Receiver operating characteristic (ROC) Curve including age, and alkaline phosphatase was performed seeking to define an appropriate cut-off value with acceptable sensitivity and specificity. The age value of 65 years old (S: $64.20 \%$ E: $51.63 \%$ AUC 0.59) and alkaline phosphatase 225 mg/dL, (S: $50.2 \%$ E: 70.46\% AUC 0.62 ) and total bilirrubin $1.6 \mathrm{mg} / \mathrm{dL}$ (S: $50 \% \mathrm{E}: 55 \%$ AUC 0.62 ) were defined as cut-off points. In order to prove the statistical relationship of these cut off values in the diagnosis of choledocholithiasis, a multivariate regression was performed (Table 6). Age OR: 1.87 ( $p$ 0.02), alkaline phosphatase OR: 2.44 ( $p$ 0.02 ) and bile duct dilation > $6 \mathrm{~mm}$ OR: 14.65 (p 0.00) (Table 6). showed stronger association with the diagnosis; total bilirrubin did not show statistical significant relationship with choledocholithiasis ( $p$ $0.391)$. 
Table 6

Multivariate analysis

\begin{tabular}{|c|c|c|c|}
\hline Variable & Odds Ratio & IC 95\% & p \\
\hline \multicolumn{4}{|c|}{ Initial Analysis } \\
\hline Age & 1.01 & $1.00-1.03$ & 0.02 \\
\hline Alkaline Phosphatase & 1.01 & $1.03-1.09$ & 0.02 \\
\hline Bile duct $>6 \mathrm{~mm}$ & 14.47 & $4.48-46.7$ & 0.00 \\
\hline AST & -- & -- - & $\ldots$ \\
\hline ALT & 1.05 & $1.00-1.05$ & 0.2 \\
\hline \multirow[t]{2}{*}{ Total Bilirubin } & 1.07 & $0.85-1.3$ & 0.547 \\
\hline & \multicolumn{3}{|c|}{ Secondary analysis. } \\
\hline Age & 1.87 & $1.06-3.31$ & 0.029 \\
\hline Alkaline Phosphatase & 2.44 & $1.4-4.26$ & 0.002 \\
\hline Bile duct $>6 \mathrm{~mm}$ & 14.65 & $4.5-47.9$ & 0.000 \\
\hline
\end{tabular}

\section{Discussion}

Criteria for risk stratification proposed by the American Society for Gastrointestinal Endoscopy (ASGE) are frequently used worldwide. Following ASGE guidelines in 2010, patients are routinely categorized according to the probability of choledocholithiasis in low risk (<10\%), intermediate risk $(10 \%-50 \%)$ and high risk $(>50 \%)$ [9]. Patients with intermediate risk benefit from additional biliary imaging $[18,19]$ and options for this include magnetic resonance cholangiopancreatography (MRCP), endoscopic ultrasound (EUS) intraoperative cholangiography (IOC), and "RendeVouz" procedure [17]. In their updated guidelines of 2019, ASGE suggests either EUS or MRCP to confirm choledocholithiasis in intermediate risk patients [20]. The differences between both classifications change the risk in 6 of our patients.

Moreover, the wide range of imaging studies paired with their varying sensitivity and specificity, has enriched the discussion regarding subsequent steps after intermediate risk classification. Meeralam et al. published a meta-analysis comparing EUS and MRCP diagnostic accuracy in which, albeit cost effectiveness and adverse events were not taken into consideration, MRCP provided good diagnostic accuracy with a sensitivity and specificity of $87 \%$ and $92 \%$ respectively [21]. By protocol and availability at our institution, patients with intermediate risk for choledocholithiasis are assessed by MRCP. From 327 MRCP performed in this study, up to $24,7 \%$ were positive for choledocholithiasis. Toro-Calle et al, found a choledocholithiasis frequency of $26.6 \%$ in patients with intermediate risk, which is comparable with our results [22]. It is worth noting that the seemingly low frequency of choledocholithiasis in this group of patients may be related to lower sensitivity $(33-71 \%)$ of MRCP in the setting of small stones $(<3 \mathrm{~mm})[23$, 
24], which was present in up to $4.72 \%$ of our patients according to ultrasonography findings. Yet, Badger et al found that most of the patients that underwent MRCP were followed with a more invasive test in $82 \%$ of cases, increasing the conflicting findings among literature [22].

Liver chemistries are measured as indirect markers of hepatobiliary disease [25], standard markers include AST, ALT, alkaline phosphatase, and bilirubin as moderate predictors of choledocholithiasis in ASGE guidelines [9]. Aminotransferases including AST and ALT are enzymes involved in the transfer of amino groups of aspartate and alanine to ketoglutaric acid and referred to as transaminases [25]; regarding these predictors for intermediate risk, there is inconsistency in literature findings, some studies have shown that gamma glutamyl transferase (GGT) has the highest sensitivity, others demonstrate superiority in ALT for choledocholithiasis [26]. In our institution, median values of total bilirubin and alkaline phosphatase were within normal limits, whereas median values of transaminases were approximately 3 times over cutoff level; GGT levels were not measured. AST and ALT were elevated more than threefold in at least $50 \%$ of patients with choledocholithiasis; nonetheless no statistical significance correlation was found. Zare et al, in a prospective study performed in 350 patients for the assessment of liver function tests in the diagnosis of common bile duct stones in patients with cholecystitis found ALT as an independent predictor of cholelithiasis (OR: 2; $P=0.04$ ) [27]. More recently, novel predictive scores are being proposed showing AUC of 0.77 and 0.76 for AST and ALT respectively in a cohort of 1089 patients [28]. Other descriptive studies have shown AST as the least sensitive parameter altered approximately $50.8 \%$ of times [29]. Thus, despite the discrepancy of liver enzyme specificity, ongoing elevation of liver tests can provide support on deciding further imaging studies [26].

Common bile duct (CBD) stones should be diagnosed on time, despite the lack of a consensus on the usefulness of liver enzymes measurement as in CBD stones; multiple studies suggest a positive association between: Alkaline phosphatase, alanine transaminase (ALT) and choledocholithiasis [26]. Isherwood et al, described the association between choledocholithiasis and echography finding of common bile duct dilation more than $6 \mathrm{~mm}$ OR $3.16(p=0.06)$, and elevated values of alkaline phosphatase OR $4.64(p<0.00)$, and alanine transaminase (OR $5.40 p<0.001)$ [26]. Nonetheless, despite in our study CBD dilation had an increased odds ratio (12,48 IC 3.97-39.18), transaminases did not show any statistically significant relationship as a diagnosis predictor.

Finally, our results and the comparison with the literature, shows the complexity in the diagnostic process, with important covariates that could mislead a timely diagnosis, and could delay the surgical management of cholelithiasis; these exposes the need of more specific and sensible predictive tools for CBD stones.

Among limitations of this study are its retrospective nature, the lack of stronger associations between the variables and the outcome and the scarcity of previous studies to compare our findings. Even though a considerable group of patients with cholelithiasis have concomitant intermediate choledocholithiasis the risk the scores available still give very loose recommendations regarding follow-up steps. 


\section{Conclusion}

There is a high percentage of patients classified as intermediate risk who do not have choledocholithiasis evidenced in cholangio-resonance. There is a persistently high variability in accuracy of imaging techniques in intermediate risk patients. CBD Dilation, Alkaline phosphatase, and age should be highly marked as predictive tools into the intermediate risk score, and could be a feasible tool to predict choledocholithiasis with acceptable sensitivity and specify. Further studies are needed to confirm our results.

\section{Abbreviations}

ASGE: The American Gastroenterology Society

CBDS: Common bile duct stone

ERCP: Endoscopic retrograde cholangio-ancreatography

MRCP: Magnetic resonance cholangio-pancreatography

ICMJE: International Committee of Medical Journal Editors

IRB: Ethics and Research Institutional Committee

EUS: Endoscopic ultrasound

IOC: Intraoperative cholangiography

GGT: Gamma glutamyl transferase

CBD: Common bile duct

ALT: Alanine aminotransferase

AST: Aspartate aminotransferase

ROC: Receiver operating characteristic

\section{Declarations}

Ethics approval and consent to participate: All procedures performed in studies involving human participants were in accordance with the ethical standards of the institutional and/or national research committee and with the 1964 Helsinki Declaration and its later amendments or comparable ethical standards. Informed consent was obtained from all individual participants included in the study, and Institutional Review Board approval (Universidad el Rosario - Hospital Universitario Mayor Méderi) was obtained. 
Consent for publication: Not apply

Avaliability of data and materials: The datasets used and/or analysed during the current study available from the corresponding author on reasonable request

Competing interest: Authors do not declare any conflict of interest

Funding: This research did not receive any specific grant from funding agencies in the public, commercial, or not-for-profit sectors.

\section{Author's contributions:}

Felipe Giron, MD, MSc, Lina Marcela Rodriguez, MD, Carlos Rey, MD, Danny Conde MD, MsC: Make substantial contributions to conception and design, acquisition of data, analysis and interpretation of data.

David Venegas MD: Participate in drafting the article and revising it critically for important intellectual content.

Susana Rojas MD, MSc: Participate in drafting the article and revising it critically for important intellectual content.

Marco Vanegas, MD: Participate in drafting the article and revising it critically for important intellectual content.

Fernando Gutierrez, MD: Participate in drafting the article and revising it critically for important intellectual content.

Ricardo Nassar, MD MSc: Participate in drafting the article and revising critically for important intellectual content. Give final approval of the version to be submitted and any revised version.

Daniel Jimenez MD: Participate in drafting the article and revising critically for important intellectual content.

Acknowledgements: To our patients

\section{References}

1. Baiu I, Hawn MT. choledocholithiasis. JAMA. 2018 Oct 9;320(14):1506. doi: 10.1001/jama.2018.11812. PMID: 30304429.

2. Paumgartner G, Sauerbruch T. Gallstones: pathogenesis. Lancet. 1991 Nov 2;338(8775):1117-21. doi: 10.1016/0140-6736(91)91972-w. PMID: 1682550.

3. Tazuma S. Gallstone disease: Epidemiology, pathogenesis, and classification of biliary stones (common bile duct and intrahepatic). Best Pract Res Clin Gastroenterol. 2006;20(6):1075-83. doi: 
10.1016/j.bpg.2006.05.009. PMID: 17127189.

4. Cai JS, Qiang S, Bao-Bing Y. Advances of recurrent risk factors and management of choledocholithiasis. Scand J Gastroenterol. 2017 Jan;52(1):34-43. doi:

10.1080/00365521.2016.1224382. Epub 2016 Sep 9. PMID: 27610642.

5. Costi R, Gnocchi A, Di Mario F, Sarli L. Diagnosis and management of choledocholithiasis in the golden age of imaging, endoscopy and laparoscopy. World J Gastroenterol 2014; 20(37): 1338213401 [PMID: 25309071 DOI: 10.3748/wjg.v20.i37.13382]

6. Virzì V, Ognibene NMG, Sciortino AS, Culmone G, Virzì G. Routine MRCP in the management of patients with gallbladder stones awaiting cholecystectomy: a single-centre experience. Insights Imaging. 2018 Oct;9(5):653-659. doi: 10.1007/s13244-018-0640-3. Epub 2018 Jul 5. PMID: 29978345; PMCID: PMC6206385.

7. Badger WR, Borgert AJ, Kallies KJ, Kothari SN. Utility of MRCP in clinical decision making of suspected choledocholithiasis: An institutional analysis and literature review. Am J Surg. 2017 Aug;214(2):251-255. doi: 10.1016/j.amjsurg.2016.10.025. Epub 2016 Dec 1. PMID: 27986260.

8. Aleknaite A, Simutis G, Stanaitis J, Valantinas J, Strupas K. Risk assessment of choledocholithiasis prior to laparoscopic cholecystectomy and its management options. United European Gastroenterol J. 2018 Apr;6(3):428-438. doi: 10.1177/2050640617731262. Epub 2017 Sep 6. PMID: 29774157; PMCID: PMC5949968.

9. ASGE Standards of Practice Committee, Buxbaum JL, Abbas Fehmi SM, et al. ASGE guidelines on the role of endoscopy in the evaluation and management of choledocholithiasis. Gastrointest Endosc. 2019;89(6):1075-1105.e15. doi:10.1016/j.gie.2018.10.001

10. Gillaspie DB, Davis KA, Schuster KM. Total bilirubin trend as a predictor of common bile duct stones in acute cholecystitis and symptomatic cholelithiasis. Am J Surg. 2019 Jan;217(1):98-102. doi: 10.1016/j.amjsurg.2018.06.011. Epub 2018 Jun 18. PMID: 29929909.

11. Mandelia A, Gupta AK, Verma DK, Sharma S. The Value of Magnetic Resonance CholangioPancreatography (MRCP) in the Detection of choledocholithiasis. J Clin Diagn Res. 2013 Sep;7(9):1941-5. doi: 10.7860/JCDR/2013/6158.3365. Epub 2013 Sep 10. PMID: 24179904; PMCID: PMC3809643.

12. ASGE Standards of Practice Committee, Buxbaum JL, Abbas Fehmi SM, Sultan S, Fishman DS, Qumseya BJ, Cortessis VK, Schilperoort H, Kysh L, Matsuoka L, Yachimski P, Agrawal D, Gurudu SR, Jamil LH, Jue TL, Khashab MA, Law JK, Lee JK, Naveed M, Sawhney MS, Thosani N, Yang J, Wani SB. ASGE guideline on the role of endoscopy in the evaluation and management of choledocholithiasis. Gastrointest Endosc. 2019 Jun;89(6):1075-1105.e15. doi: 10.1016/j.gie.2018.10.001. Epub 2019 Apr 9. PMID: 30979521.

13. Polistina FA, Frego M, Bisello M, Manzi E, Vardanega A, Perin B. Accuracy of magnetic resonance cholangiography compared to operative endoscopy in detecting biliary stones, a single center experience and review of literature. World J Radiol. 2015 Apr 28;7(4):70 - 8. doi: 10.4329/wjr.v7.i4.70. PMID: 25918584; PMCID: PMC4404370. 
14. Qiu Y, Yang Z, Li Z, Zhang W, Xue D. Is preoperative MRCP necessary for patients with gallstones? An analysis of the factors related to missed diagnosis of choledocholithiasis by preoperative ultrasound. BMC Gastroenterol. 2015 Nov 14;15:158. doi: 10.1186/s12876-015-0392-1. PMID: 26577949; PMCID: PMC4650402.

15. Reid J, Dolan R, Patel M, Fleming R, Young D, Hair A. Size of common bile duct stones on MRCP predicts likelihood of positive findings at ERCP. Surgeon. 2017 Jun;15(3):119-122. doi: 10.1016/j.surge.2015.11.001. Epub 2015 Dec 10. PMID: 26688059

16. Giljaca V, Gurusamy KS, Takwoingi Y, Higgie D, Poropat G, Štimac D, Davidson BR. Endoscopic ultrasound versus magnetic resonance cholangiopancreatography for common bile duct stones. Cochrane Database Syst Rev. 2015 Feb 26;2015(2):CD011549. doi: 10.1002/14651858.CD011549. PMID: 25719224; PMCID: PMC6464848.

17. ASGE Standards of Practice Committee, Maple JT, Ben-Menachem T, Anderson MA, Appalaneni V, Banerjee S, Cash BD, Fisher L, Harrison ME, Fanelli RD, Fukami N, Ikenberry SO, Jain R, Khan K, Krinsky ML, Strohmeyer L, Dominitz JA. The role of endoscopy in the evaluation of suspected choledocholithiasis. Gastrointest Endosc. 2010 Jan;71(1):1-9. doi: 10.1016/j.gie.2009.09.041. PMID: 20105473.

18. Urbach DR, Khajanchee YS, Jobe BA, Standage BA, Hansen PD, Swanstrom LL. Cost-effective management of common bile duct stones: a decision analysis of the use of endoscopic retrograde cholangiopancreatography (ERCP), intraoperative cholangiography, and laparoscopic bile duct exploration. Surg Endosc. 2001 Jan;15(1):4-13. doi: 10.1007/s004640000322. PMID: 11178753.

19. Liu TH, Consorti ET, Kawashima A, Tamm EP, Kwong KL, Gill BS, Sellin JH, Peden EK, Mercer DW. Patient evaluation and management with selective use of magnetic resonance cholangiography and endoscopic retrograde cholangiopancreatography before laparoscopic cholecystectomy. Ann Surg. 2001 Jul;234(1):33-40. doi: 10.1097/00000658-200107000-00006. PMID: 11420481; PMCID: PMC1421945.

20. ASGE Standards of Practice Committee, Buxbaum JL, Abbas Fehmi SM, Sultan S, Fishman DS, Qumseya BJ, Cortessis VK, Schilperoort H, Kysh L, Matsuoka L, Yachimski P, Agrawal D, Gurudu SR, Jamil LH, Jue TL, Khashab MA, Law JK, Lee JK, Naveed M, Sawhney MS, Thosani N, Yang J, Wani SB. ASGE guideline on the role of endoscopy in the evaluation and management of choledocholithiasis. Gastrointest Endosc. 2019 Jun;89(6):1075-1105.e15. doi: 10.1016/j.gie.2018.10.001. Epub 2019 Apr 9. PMID: 30979521.

21. Meeralam Y, Al-Shammari K, Yaghoobi M. Diagnostic accuracy of EUS compared with MRCP in detecting choledocholithiasis: a meta-analysis of diagnostic test accuracy in head-to-head studies. Gastrointest Endosc. 2017 Dec;86(6):986-993. doi: 10.1016/j.gie.2017.06.009. Epub 2017 Jun 20. PMID: 28645544.

22. Toro-Calle Jerónimo, Guzmán-Arango Carolina, Ramírez-Ceballos Mariana, Guzmán-Arango Natalia. Are the ASGE criteria sufficient to stratify the risk of choledocholithiasis?. Rev Col Gastroenterol [Internet]. 2020 Sep [cited 2021 July 06]; 35(3): 304-310. Epub Mar 01, 2021. https://doi.org/10.22516/25007440.464. 
23. Zidi SH, Prat F, Le Guen O, Rondeau Y, Rocher L, Fritsch J, Choury AD, Pelletier G. Use of magnetic resonance cholangiography in the diagnosis of choledocholithiasis: prospective comparison with a reference imaging method. Gut. 1999 Jan;44(1):118-22. doi: 10.1136/gut.44.1.118. PMID: 9862837; PMCID: PMC1760072.

24. Boraschi P, Neri E, Braccini G, Gigoni R, Caramella D, Perri G, Bartolozzi C. choledocholithiasis: diagnostic accuracy of MR cholangiopancreatography. Three-year experience. Magn Reson Imaging. 1999 Nov;17(9):1245-53. doi: 10.1016/s0730-725x(99)00075-2. PMID: 10576709.

25. Kwo PY, Cohen SM, Lim JK. ACG Clinical Guideline: Evaluation of Abnormal Liver Chemistries. Am J Gastroenterol. 2017 Jan;112(1):18-35. doi: 10.1038/ajg.2016.517. Epub 2016 Dec 20. PMID: 27995906.

26. Isherwood J, Garcea G, Williams R, Metcalfe M, Dennison AR. Serology and ultrasound for diagnosis of choledocholithiasis. Ann R Coll Surg Engl. 2014 Apr;96(3):224-8. doi: 10.1308/003588414X13814021678033. PMID: 24780789; PMCID: PMC4474054.

27. Zare M, Kargar S, Akhondi M, Mirshamsi MH. Role of liver function enzymes in diagnosis of choledocholithiasis in biliary colic patients. Acta Med Iran. 2011;49(10):663-6. PMID: 22071641.

28. Kokoroskos N, Peponis T, Lee JM, El Hechi M, Naar L, Nederpelt C, Gaitanidis A, Mendoza AE, Saillant $\mathrm{N}$, Kaafarani H, King D, Velmahos G, Fagenholz P. The Role of Transaminases in Predicting choledocholithiasis. A Novel Predictive Composite Score Development in a Cohort of 1089 Patients Undergoing Laparoscopic Cholecystectomy. Am Surg. 2021 Mar 12:3134821998664. doi: 10.1177/0003134821998664. Epub ahead of print. PMID: 33710916.

29. Pereira-Limâ JC, Jakobs R, Busnello JV, Benz C, Blaya C, Riemann JF. The role of serum liver enzymes in the diagnosis of choledocholithiasis. Hepatogastroenterology. 2000 NovDec;47(36):1522-5. PMID: 11148992.

\section{Figures}




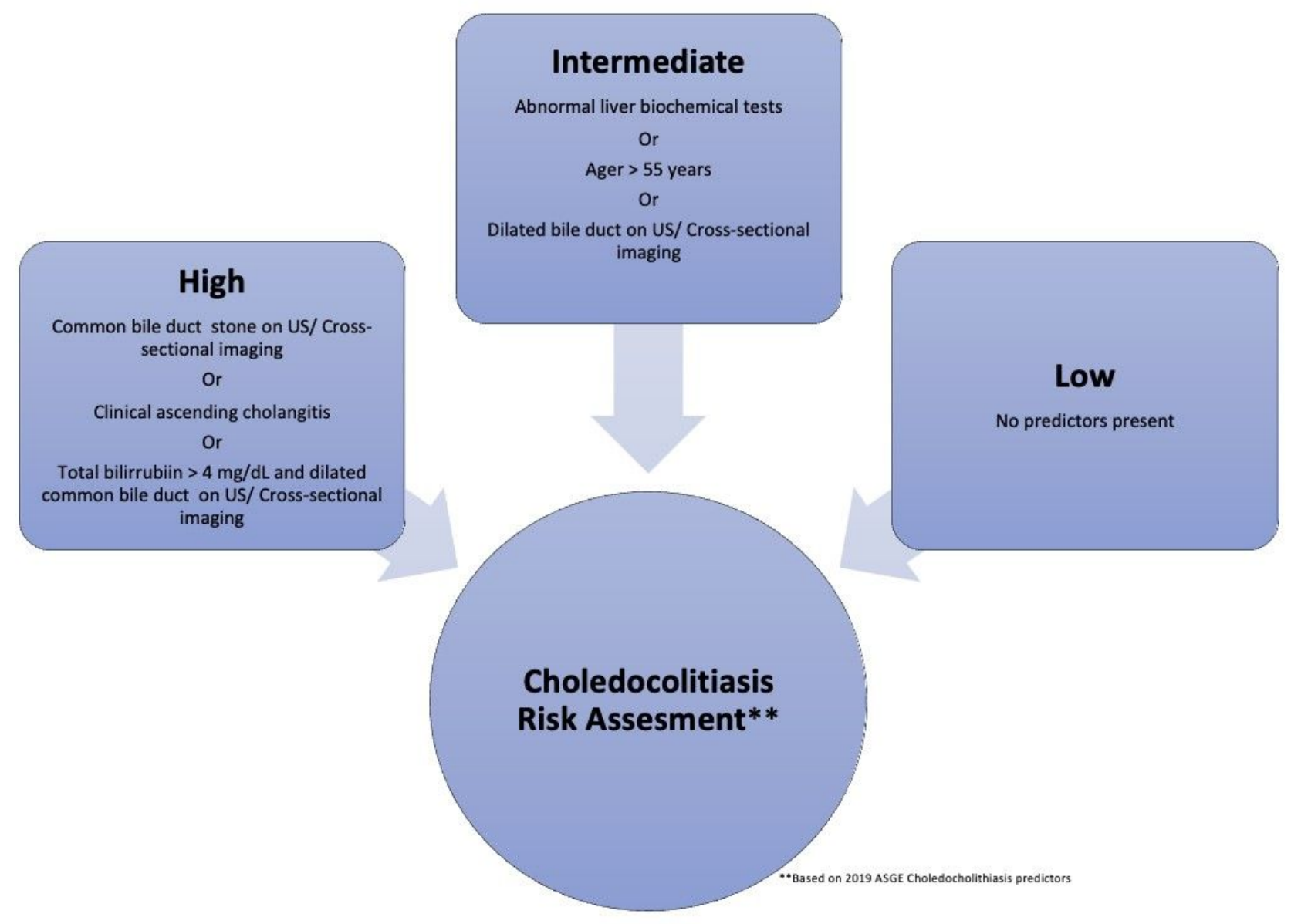

Figure 1

Choledocolitiasis Risk Assesment

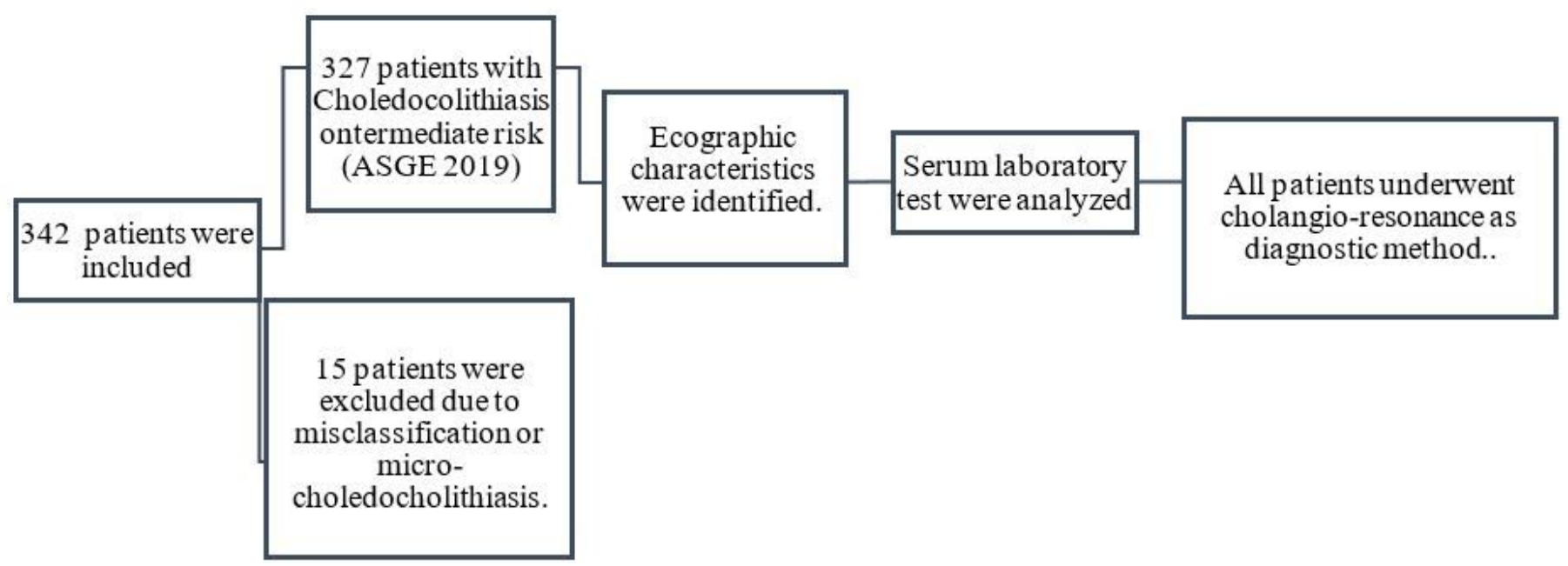

Figure 2

Patients inclusion process 